\title{
OPTIMIZATION OF DENTAL IMPLANTATION COMBINED WITH CLOSED SINUS LIFT IN PATIENTS WITH LOW MAXILLARY SINUS FLOOR
}

\section{Sergey Kupryakhin', Alexander Lepilin ${ }^{7 *}$, Vyacheslav Kupryakhin'2, Dmitry Domenyuk ${ }^{3}$}

\author{
${ }^{1}$ Department of Surgical Dentistry and Maxillofacial Surgery, Saratov \\ State Medical University, Saratov, Russia \\ ${ }^{2}$ Department of Medical Law and Bioethics, Samara State Medical \\ University, Samara, Russia \\ ${ }^{3}$ Department of General Dentistry and Child Dentistry, Stavropol State \\ Medical University, Stavropol, Russia
}

*Corresponding Author: lepilins@mail.ru
A B STRACT - The experiment carried out on autopsied specimens, helped develop a model of minimally invasive surgical intervention in the upper jaw. Using the developed and tested dental implant allowed its primary fixation, and also, without using complex devices, it allowed introducing osteogenic material under the Schneider membrane dome, evenly distributing it around the implant. The development and implementation of the proposed implants that can ensure sufficient primary stabilization with immediate sinus lift will allow maximum use of the patient's own bone, which was preserved to a minimum extent.

KEYWORDS - dental implantation, sinus lift, osteogenic materials, dental implants

\section{INTRODUCTION}

One of the issues that dental surgeons have to face when it comes to dental implantation in the distal upper jaw areas is insufficient bone quantity and quality [20-31]. The recent years have witnessed wide implementation of a method that allows increasing the volume of bone tissue at the alveolar bone in the maxillary sinus bottom area, the sinus lift surgery $[1-3,5,7,8,10-12,14,15,17]$. However, dentists often experience failures while performing such surgeries, including damaging the maxillary sinus mucous membrane; unsuccessful choice of osteoplastic material for the development of sufficient volume; infection in the sinus followed with serous or purulent sinusitis; migration of implants into the sinus cavity; oroantral fistula. Resorption of the introduced material or its replacement with connective tissue without bone tissue development can often be observed $[1,4,7-9,11,19]$.
Article history:

Submitted 3 May 2019

Accepted 29 July 2019
Recent publications offer various modifications of the surgery aimed at eliminating such complications. Controlled detachment and elevation of the maxillary sinus mucous membrane followed by the introduction of the required amount of augment with minimal operative injury can be reached through using various methods of "closed" ("soft", "balloon", etc.) sinus lift. However, all of them are associated with bone injury, and most of the protocol is performed "blindly" $[3,6,8,10,12,13,15-18]$. An implant installed in a single step, due to poor primary stabilization, can get mobile and start migrating, which will increase the rehabilitation time. There is no guarantee of the augmentation optimal distribution, as well as there are no clear indications for carrying out this or any other type of intervention, depending on the anatomical and clinical context $[3,9,12,13,19]$.

On the other hand, closed surgical intervention (without making an opening on the maxillary sinus anterior wall) which is definitely less traumatic and allows narrowing the surgical field to a minimum, still implies performing this operation blindly, while inserting the graft into the maxillary sinus, in turn, presents another issue, both in view of the plastic specifics and the introduction method, which complicates the surgery $[3,10,11,14,16,17,32-40]$. The methods and models of implants we propose may help solve issues that dental surgeons face when using methods of closed sinus lift, as well as expand indications for single-stage implant placement, which helps to reduce the time needed for rehabilitation. Therefore, dental implantation in the upper jaw in case of significant atrophy of the alveolar process has not been fully studied yet, while the currently proposed methods of closed sinus lift with singlestage implantation are not always sufficient to solve the said issues.

\section{Aim of study:}

development and experimental approval for closed sinus lift with single-stage implantation in patients with a low maxillary sinus floor in order to increase the efficiency and to reduce the duration of dental treatment. 


\section{MATERIALS AND METHODS}

The team of authors developed dental implants models (Patents RU 2395249, RU 155741), and a dental implantation method in case of significant atrophy of the alveolar process in the upper jaw (Patent RU 26000150. 2016); besides, for clinical purposes an intraosseous self-tapping construction was designed, which simplifies the surgery protocol (Patent RU 182012. 2018).

For bioethical considerations, prior to proposing a method for clinical use, it was important to prove experimentally that the design would ensure primary stability for the implant, and that it would also perform successfully the role of an osteoplastic material conductor with the development of a uniformly filled dome made up by the Schneider membrane and the maxillary sinus bottom.

The dental implant we developed contains an intraosseous element shaped like a hollow cylinder that has a thread on the outside for fixation in the bone, and an internal thread to connect with the internal element thread. The inner element is designed as a cylindrical rod with a thread on the outer surface and a hemispherical base; it has an axial through hole for the cannula, whereas the hole is connected to several evenly spaced holes in the hemispherical base of the inner element to pass the osteopathic gel into the sinus cavity and subsequent bone tissue germination into the holes, while the inner element has a measuring scale or marks inside its mouth. The inner element of the proposed design easily perforates the maxillary sinus bottom and exfoliates the mucous membrane. The locking element prevents the sinus perforation by the inner element. The invention allowed simplifying and reducing the invasiveness of dental implantation with significant atrophy of the maxillary alveolar process, increasing the bone tissue by $5-7 \mathrm{~mm}$, enhancing the implant attachment reliability in the maxillary bone tissue.

To develop the installation technique of such implants, we carried out an experiment at the Department of Forensic Medicine, Samara State Medical University. We divided the whole operation into two stages: at the first stage we set a goal — to obtain primary fixation of the intraosseous element while not perforating the bottom of the maxillary sinus (Fig. 1).

The second stage implied creating sufficient space to introduce the osteogenic material bounded by the mucous membrane of the maxillary sinus and its bottom (Fig. 2).

Further, the location of the implant was identified and marked with a tapered drill to place the main hole. The major drill formed a hole, the stop (determining the distance to the sinus bottom) located on the drill did not allow the bottom to be perforated through to the sinus. An implant driver was used to screw-drive the intraosseous element all the way (Fig. 3).

For visual control, a "window" was made on the vestibular wall of the sinus, which allowed controlling the experiment (Fig. 4).

Then, using a special implanter, following the intraosseous element's inner thread, the inner element was screwed in up to the stop. Further, the movement went on until the typical feeling of the bone floor perforation in the maxillary sinus. Slow introduction of the inner element raised the mucous membrane of the sinus cavity bottom, while the degree of risk was assessed after each rise through the localization of the inner element's intraoral part (Fig. 4). These measures resulted in a Schneider membrane dome following (Fig. 2). Next, the implant driver was released, and using a special cannula, $0.3-0.5 \mathrm{ml}$ of an osteogenic simulator (for clarity, we prepared an osteoplastic material simulator - an osteogenic Polistom gel, stained with a caries detector) was pressed in. Therefore, the inner element of the designed dental implant was installed before creating a 5-7 mm high dome filled with an osteoplastic material simulator (Fig. 5).

Subsequently, through the "window" we visualized the location of the osteogenic gel, which was evenly distributed in all areas, and filled the entire submembrane space (Fig.6).

\section{RESULTS AND DISCUSSION}

We carried out 8 experimental surgeries on both the right and left sides of the upper jaw at the chewing teeth area. In seven cases, primary fixation of the intraosseous element was achieved (in one case, the intraosseous element fell into the maxillary sinus). In all the cases, perforating the maxillary sinus bottom with an internal element and exfoliating the mucous membrane presented no issue. In the all cases, the gel easily penetrated into the cavity shaped by the Schneider membrane dome and the maxillary sinus bottom, and filled the said cavity; moreover, it enhanced its volume.

\section{ONCLUSION}

The experimental studies suggest that the proposed method of closed sinus lift with a single-stage implantation in patients with a low maxillary sinus bottom (less than 7-8 $\mathrm{mm}$ ), helps expand the range of indications for dental implantation. The proposed implant models and operational benefit reduce significantly the risk of developing uncontrolled complications. The development and implementation of individual implants that can ensure primary stabilization with a single-stage sinus lift will allow maximum use of 
S T O M A TOLOG Y

\section{EXPERIMENTAL RESEARCH}

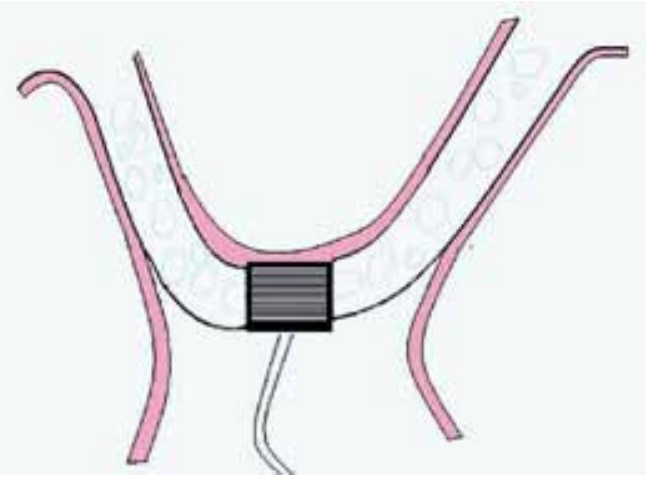

Fig. 1. Installation of the intraosseous element of the proposed dental implant without perforation of the maxillary sinus bottom

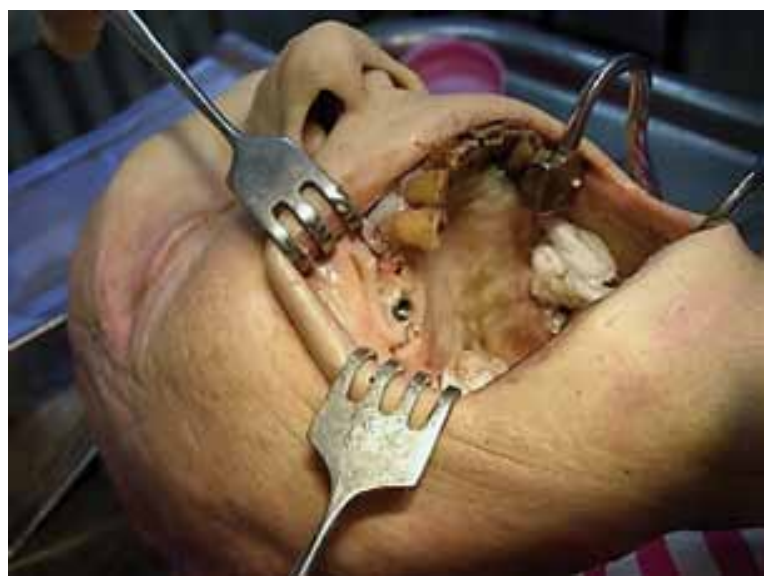

Fig. 3. Installing the intraosseous part of the implant

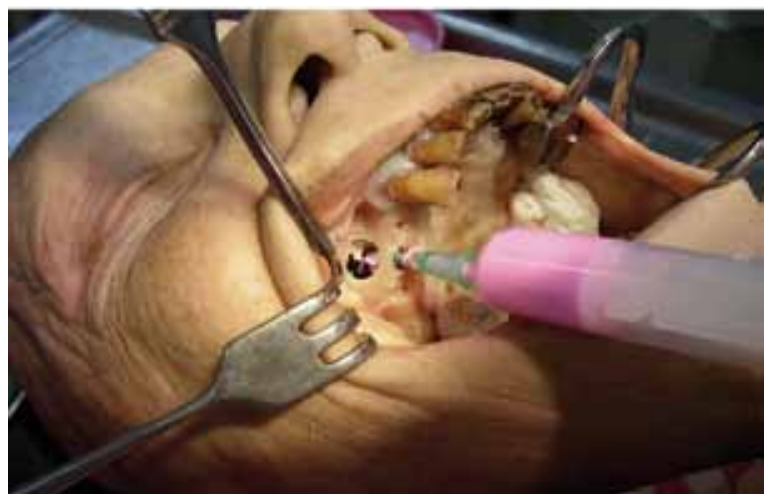

Fig. 5. Visualization of the osteoplastic material simulator pathway
| archiv euromedica $2019 \mid$ vol. $9 \mid$ num. 2 |

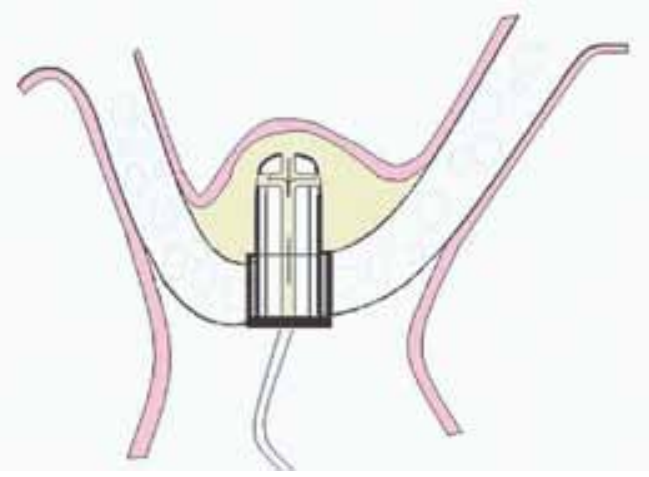

Fig. 2. Installation diagram of the proposed implant's inner part and the path of movement for the osteopathic material

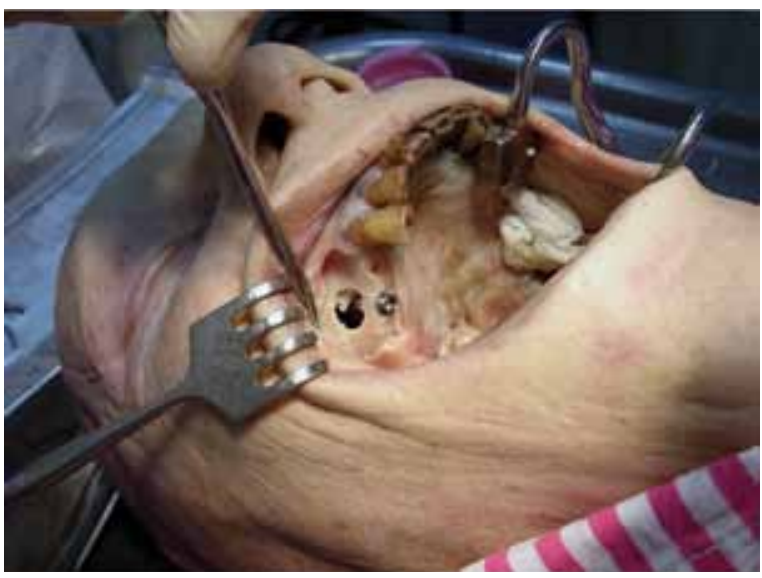

Fig. 4. Visualization of the osteoplastic material pathway using a "window" on the maxillary sinus vestibular wall

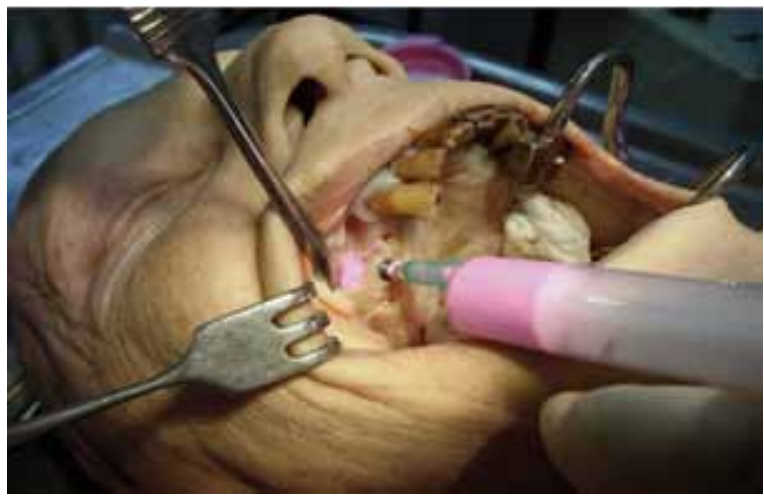

Fig. 6. The osteoplastic material fills the entire cavity shaped by the Schneider membrane dome and the sinus bottom 
the patient's own bone, which has been preserved, even though to a minimum extent.

\section{REFERENCES}

1. Amkhadova M.A., Nikitin A.A., Sipkin A.M. Risk factors and an algorithm for predicting postoperative complications with an increase in bone tissue in the region of the bottom of the maxillary sinus. // Dental journal. - 2009. - №2, June. - P. 182-184.

2. Cricchio G., Imburgia M., Sennerby L., LuNDGREN S. Immediate loading of the implants placed along with raising of a sinus membrane in a back atrophic upper jaw: a two-year research on 10 patients // Clin Implant Dent Relat Res. 2014 Aug; 16 (4): P. 609-617.

3. Esposito M., Felice P., Worthington H.V. Interventions on replacement of the absent teeth: procedures of augmentation of a genyantrum // 2014 on May 13; (5): CD008397. doi: 10.1002 / 14651858. CD008397.pub2.

4. Felice P., Pistilli R., Piattelli M., Soardi E. Barausse C., Esposito M. 1 stage against 2-landmark side procedures a sine lifting: 1-year post-load results of multicenter randomized controlled study // Eur J Oral Implantol. Spring of 2014; 7(1): P.65-75.

5. Fouad W., Osman A., Atef M., Hakam M. The directed genyantrum bottom height with use of a deproteined bull bone in comparison with a beztransplantatsionny membrane of Schneider with simultaneous placement of an implant: randomized clinical test.// Clin Implant Dent Relat Res. 2018 Jun; 20 (3): P. 424-433.

6. Gatti F., Gatti C., Tallarico M., Tommasato G., Meloni S.M., Chiapasco M. Height of a membrane of a maxillary bosom with use of a special system of drilling and hydraulic pressure: 2-year prospektivny kogortny research.// Int J of Parodontologiya Vosstanovitelnaya of Vmyatin. $2018 \mathrm{Jul} /$ August; 38 (4): P. 593-599.

7. Khouly I., Veitz-Keenan A. There are not enough proofs for a sine lifting of short implants for rehabilitation of tooth implants / Evid on the basis of the Dent. 2015 Mar; 16 (1): P. 21-32.

8. Кiм D.Y., IтOH Y., KANG T.H. Evaluation of the Effectiveness of a Water Lift System in the Sinus Membrane-Lifting Operation as a Sinus Surgical Instrument // Clin Implant Dent Relat Res. - 2010.- Jun Vol. 25. Epub ahead of print.

9. Noон N. Impact of perforation of a membrane of Schneider on survival of a back maxillary implant.// J Health of an oral cavity 2013 June; 5 (3): P. 28-34.

10. Pozzi A Minimum invasive transkrestalny directed sine lifting (TGSL): clinical prospective cohort trial up to 52 months.//Clin Implant Dent Relat Res. 2014 Aug; 16 (4): P. 582-93.

11. RagucCi G.M. , ElNayef B., SUÁrez-López Del Amo F., Wang H.L. , Hernández-Alfaro F., Gargallo-Albiol J . The impact of influence of tooth implants in a bosom cavity on survival and frequency of complications: systematic overview// Implant dent 2019 Feb 5;5(1): P. 6.

12. Ramirez Fernández M.P., Gehrke S.A., Mazón P., Calvo-Guirado J.L., De Aza P.N. Stability of an implant of the biological hydroxyapatites used in stomatology // Materials (Basel). 2017 June 12; 10 (6).

13. Solakoglu Ö., Götz W., Kiessling M.C., Alt C., Schmitz C., Alt E.U. The improved directed regeneration of a stone the combined use of unmodified, fresh autologous adipose of derivative regenerative cells and plasmas of the rich in growth factors: the report on the first in - the person of a case and prowatching literature / / World J stem cells of 2019 on February 26; 11 (2): P. 124-146.

14. Spinelli D., DE Vico G., Condò R., Ottria L, ARCURI C. The Transkrestalny directed sine lifting without transplant materials: 36 months of clinical prospective trial.// Oral Implantol (Rome). 2016 on July 25; 8 (2-3): P. 74-86.

15. Tallarico M., Better H., De Riv G., Meloni S.M. A novel implant system dedicate to hydraulic Schneiderian membrane elevation and simultaneously bone graft augmentation: An up-to 45 months retrospective clinical study // J Craniomaxillofac Surg. 2016 Aug;44(8): P. 1089-94.

16. Tallarico M., Meloni S.M., Xhanari E., Pisano M., Cochran D.L. Minimum invasive procedure of increase in a sine with use of the special hydraulic device for a sine lifting: a prospective research of the clinical, radiological and focused on the patient outcome // Int J of Parodontologiya Vosstanovitelnaya of Vmyatin. 2017 January/February; 37 (1): P. 125-135.

17. Tallarico M., Cochran D.L., Xhanari E., Dellavia C., Canciani E., Mijiritsky E., MeloNI S.M. Crystal sine lifting with use of an implant with the internal-shaped channel: in 1 year after loading results of a prospektivny kogortny research // Eur J Oral Implantol. 2017;10(3): P. 325-336.

18. Torres J., Tamimi F., Martinez P.P., AlKhraisat M.H., Linares R., HernándeZ G., TORRes-Macho J., López-Cabarcos E. Effect of platelet-rich plasma on sinus lifting: a randomizedcontrolled clinical trial// J Clin Periodontal. - 2009. - Aug Vol.36(8) . - P. 677-687.

19. Zill A., Precht C., Beck-Broichsitter B., SehNER S., SMeEts R., Heiland M., RENDENBaCH C. HeNNingSEN A. The implants inserted with an oseotome sine floor raising without transplant-5-year post-load retrospective research // Eur J oral implantologist of 2016; 9 (3): 277-289.

20. Dmitrienko T.D., Domenyuk D.A., PorfyriaDIS M.P., ARUTYUNOVA A.G., KONDRATYUK A.A., Subbotin R.S. Connection between clini$\mathrm{cal}$ and radiological torque of medial incisors at physiological occlusion. Archiv Euro Medica, 2019; Vol. 9; 1: 29-37. https://doi.org/10.35630/2199$885 \mathrm{X} / 2019 / 9 / 1 / 29$ 
21. DMitrienko S.V., Fomin I.V., Domenyuk D.A., Kondratyuk A.A., Subbotin R.S. Enhancement of research method for spatial location of temporomandibular elements and maxillary and mandibular medial incisors. Archiv Euro Medica, 2019; Vol. 9; 1: 38-44. https://doi.org/10.35630/2199$885 \mathrm{X} / 2019 / 9 / 1 / 38$

22. DMitrienko S.V., Davydov B.N., V.V. ShKarin, DOMENYUK D.A. Algorithm for determining the size of artificial teeth by the morphometric parameters of the face in people with full adentia. Dentistry. 2018; 97(6): 57-60. DOI - 10.17116/stomat20189706157

23. Korobkeev A.A., Domenyuk D.A., ShKarin V.V., DMitrienko S.V. Types of facial heart depth in physiological occlusion. Medical news of North Caucasus. 2018. - Vol. 13. - № 4. - P. 627-630. (In Russ., English abstract). DOI - https://doi.org/10.14300/ mnnc.2018.13122

24. Domenyuk D.A., ShKarin V.V., Porfiriadis M.P., DMitrienko D.S., DMitrienko S.V. Algorithm for forecasting the shape and size of dent arches front part in case of their deformations and anomalies. Archiv EuroMedica, 2017; Vol. 7; 2: 105-110.

25. Domenyuk D.A., LePilin A.V., Fomin I.V., DMITRIENKo S.V. Improving odontometric diagnostics at jaw stone model examination. Archiv EuroMedica, 2018; Vol. 8; 1: 34-35.

26. Lepilin A.V., Fomin I.V., Domenyuk D.A., DMitrienko S.V. Diagnostic value of cephalometric parameters at graphic reproduction of tooth dental arches in primary teeth occlusion. Archiv EuroMedica, 2018; Vol. 8; 1: 37-38.

27. Korobkeev A. A., Domenyuk D. A., ShKarin V. V., DMitrienko S. V., Mazharov V. N. Variability of odontometric indices in the aspect of sexual dimorphism. Medical News of North Caucasus. 2019;14(1.1):103-107. DOI - https://doi. org/10.14300/mnnc.2019.14062 (In Russ.)

28. DMitrienko S.V., Domenyuk D.A., FischeV S.B., Subbotin R.S. Dynamics of periodontal fixing capacity through orthodontic treatment employing edgewise technique // Archiv EuroMedica. 2019. Vol. 9; 1: 151-152. https://doi.org/10.35630/2199$885 \mathrm{X} / 2019 / 9 / 1 / 151$

29. Dmitrienko S.V., Domenyuk D.A., Puzdyryova M.N. Manufacturing methods for individual aligners and trainers from thermoplasts fnd clinical indications for their application // Archiv EuroMedica. 2019. Vol. 9; 1: 153-154. https://doi.org/10.35630/2199$885 \mathrm{X} / 2019 / 9 / 1 / 153$

30. Dmitrienko S.V., Lepilin A.V., Domenyuk D.A., KondRATYUK A.A. Clinical meaning of methods for identifying variability of mental prominence location // Archiv EuroMedica. 2019. Vol. 9; 1: 45-46. https:// doi.org/10.35630/2199-885X/2019/9/1/45

31. Fischev S.B., Puzdyryova M.N., Dmitrienko S.V., Domenyuk D.A., KondratyuK A.A. Morphological features of dentofacial area in peoples with dental arch issues combined with occlusion anomalies
// Archiv EuroMedica. 2019. Vol. 9; 1: 162-163. https://doi.org/10.35630/2199-885X/2019/9/1/162

32. LePILIN A.V., DMitrienko S.V., DOMENYUK D.A., Puzdyryova M.N., Subbotin R.S. Dependence of stress strain of dental hard tissues and periodontal on horizontal deformation degree // Archiv EuroMedica. 2019. Vol. 9; 1: 173-174. https://doi. org/10.35630/2199-885X/2019/9/1/173

33. Porfyriadis M.P., Domenyuk D.A., ArutyuNova A.G., DMitrienko S.V. Scanning electron microscopy and X-ray spectral microanalysis in dental tissue resistance // Archiv EuroMedica. 2019. Vol. 9; 1: 177-185. https://doi.org/10.35630/2199$885 \mathrm{X} / 2019 / 9 / 1 / 177$

34. Basov A.A., IvCHENKo L.G., DoMENYUK D.A., DMitrienko T.D., Nuzhnaya C.V. The role of oxidative stress in the pathogenesis of vascular complications in children with insulinable sugar diabetes // Archiv EuroMedica. 2019. Vol. 9; 1: 136-145. https:// doi.org/10.35630/2199-885X/2019/9/1/136

35. Domenyuk D.A., Porfyriadis M.P., BudAYCHIEv G. M-A. Contemporary methodological approaches to diagnosing bone tissue disturbances in children with type 1 diabetes. Archiv EuroMedica, 2018; 8(2): 71-81.

36. DAVydov B.N., Domenyuk D.A., DMitrienko S.V. Peculiarities of microcirculation in periodont tissues in children of key age groups sufficient type 1 diabetes. Part I. Periodontology, 2019; Vol. 24; 1-24(90): 4-10. DOI: 10.25636/PMP.1.2019.1.1

37. Davydov B.N., Domenyuk D.A., DMitrienko S.V. Peculiarities of microcirculation in periodont tissues in children of key age groups sufficient type 1 diabetes. Part II. Periodontology, 2019; Vol. 24; 2-24(91): 108-119. DOI: 10.33925/1683-3759-201924-2-108-119

38. DAvydov B.N., Domenyuk D.A., BYKov I.M., IVChenko L.G., DMitrienko S.V. Modern possibilities of clinical-laboratory and $\mathrm{x}$-ray research in preclinical diagnostics and prediction of the risk of development of periodontal in children with sugar diabetes of the first type. Part I. Periodontology, 2018; Vol. 23; 3-23(88): 4-11. DOI:10.25636/PMP.1.2018.3.1

39. Domenyuk D.A., Davydov B.N., DMitrienko S.V., Sumkina O.B., Budaychiev G. M-A. Changes of the morphological state of tissue of the paradontal complex in the dynamics of orthodontic transfer of teeth (experimental study). Periodontology, 2018; Vol. 23; 1-23(86): 69-78. DOI:10.25636/ PMP.1.2018.1.15

40. Lepilin A.V., Rajgorodskij Yu.M., GrigoryeVA D.A., Erokina N.L., BAKHTEEVA G.R., DomenYUK D.A. Reasoning for the application of violet laser physiotherapy device following surgeries in the oral cavity. Archiv EuroMedica, 2018; 8(2): 111-114. 